\title{
Isolation and analysis of complement activating aggregates from synovial fluid of patients with rheumatoid arthritis using monoclonal anti-C3d antibodies
}

\author{
A E BEDWELL, ${ }^{1}$ C J ELSON, ${ }^{1} \mathrm{~S}$ D CARTER, ${ }^{1}$ P A DIEPPE, \\ C W HUTTON, AND R CZUDEK
}

From the Departments of ${ }^{1}$ Pathology and ${ }^{2}$ Medicine, Bristol University; and the ${ }^{3}$ South West Regional Transfusion Centre, Bristol

SUMMARY The complement activating aggregates in synovial fluids of patients with rheumatoid arthritis (RA) have been isolated using monoclonal IgM anti-C3d antibodies attached to solid phases, and the content of the material bound has been analysed. High levels of aggregated IgG bearing C3d were found in RA synovial fluids, and IgG was the major immunoglobulin bound from such synovial fluids by anti-C3d Sepharose. A strong correlation was shown between levels of aggregated IgG bearing C3d and complement activation, as judged by C3d levels. Significant (but less strong) relationships were also observed between C3d levels and both complement consuming and $\mathrm{Clq}$ binding activity. C3d levels and levels of aggregated IgG bearing C3d were both significantly associated with the numbers of polymorphonuclear leucocytes (PMNs) found in RA synovial fluids. From these results it is concluded that the aggregated immunoglobulins bearing C3d (particularly IgG) isolated from RA synovial fluids are responsible for activating complement and attracting PMNs into the joint space. Radioimmunoassay showed no correlation, however, between levels of aggregated IgG (or IgM) bearing C3d and rheumatoid factor (RF) activity bound by anti-C3d. In addition, the material bound by anti-C3d Sepharose from most synovial fluid polyethylene glycol precipitates did not contain either IgM or IgG RF. Thus both techniques show that the majority of complexes bearing C3d do not contain RF. As the complement fixing aggregates apparently contain only immunoglobulin and complement components the results raise the problem of how the aggregates are formed. It is suggested that RA IgG may remain aggregated after either antigen or antibody (RF) has dissociated from the complex.

Key words: aggregated IgG bearing C3d, C3d levels, PMN numbers, rheumatoid factor.

It has been suggested that the high numbers of PMNs which are found in synovial fluids of patients with RA are attracted there by chemotactic agents, generated as a result of antigen-antibody complexes initiating complement breakdown. ${ }^{1}$ There is no doubt that IgG aggregates occur in the synovial fluids of patients with RA, ${ }^{2}$ nor that local complement activation takes place. ${ }^{3-5}$ Complexes containing $\mathrm{IgG}$ are thought to trigger the activation because there is some relation between levels of high

Accepted for publication 24 June 1986.

Correspondence to $\mathrm{Dr} \mathrm{C} J$ Elson, Immunopathology Group. Department of Pathology, University of Bristol, Bristol BS8 1TD. molecular weight IgG and anticomplementary activity in synovial fluids. ${ }^{2}$ In addition, analysis of the joint material which has bound complement shows it to be mainly IgG with some IgM. ${ }^{6}$ Recently we examined the relation between the complexes which contain RF and those which activate complement in the sera and synovial fluids from patients with rheumatic diseases. ${ }^{78}$ Essentially, this was done by isolating the complexes which had fixed complement and asking if they contained RF. The results showed that sera from patients with RA and systemic vasculitis had high levels of complexes which contained both rheumatoid factor and fixed comple- 
ment. Unexpectedly, these complexes were detected in only a minority of synovial fluids from other patients with RA and then at lower levels. The failure to find proteins other than immunoglobulins and complement components in complexes isolated from synovial fluids, ${ }^{69}$ together with the correlation between complement depletion and RF titres, ${ }^{10}$ has led a number of authors to infer that the complexes which are activating complement consist of IgG (as antigen) and RF. In view of the apparent discrepancy of these findings with our results it seemed necessary to re-evaluate the content of the complement activating material in synovial fluid. This report describes the use of IgM monoclonal antiC3d antibodies to isolate such material (IgM is not an antigen for RF and thus RF will not bind directly to solid phases to which IgM anti-C3d antibodies have been attached) and experiments designed to test $(a)$ whether the immunoglobulins bound by this antibody are those responsible for activating complement in RA synovial fluid and are thus contributing to the attraction of PMNs into the joint; and $(b)$ whether the material bound by the solid phase antibody contains RF.

\section{Patients and methods}

\section{PATIENTS}

All patients fulfilled the American Rheumatism Association criteria for classical or definite RA. Of these patients, 44 were female, 21 male, $86 \%$ seropositive by latex agglutination, and $94 \%$ by radioimmunoassay for IgM rheumatoid factor. Their mean age was 60 years and the average duration of their disease 12 years. Synovial fluids were obtained from therapeutic aspiration of actively inflamed knee joints. The patients were receiving a variety of non-steroidal anti-inflammatory and slow acting antirheumatic drugs. Each sample was divided into three portions: the first was used to measure cell and differential counts; the second was collected in ethylenediaminetetra-acetic acid (EDTA), centrifuged within two hours of collection to remove the cells, and stored in aliquots at $-70^{\circ} \mathrm{C}$; and the third was centrifuged within two hours of collection and stored in aliquots at $-70^{\circ} \mathrm{C}$.

Synovial fluids were also obtained from 11 patients with an active crystal synovitis (three with gout, eight with pseudogout) whose joints were aspirated for diagnostic or therapeutic reasons. Sera were from normal healthy volunteers.

POLYETHYLENE GLYCOL (PEG)

PRECIPITATION

Samples were diluted $1: 2$ in borate buffered saline pH 8.3 containing $0.5 \mathrm{mM}$ EDTA. Polyethylene glycol (PEG) 6000 was added to a concentration of $2.5 \%$ and the mixture held at $4^{\circ} \mathrm{C}$. The precipitate was centrifuged ( $3000 \mathrm{~g}$ for $15 \mathrm{~min}$ ), washed in $2.5 \%$ PEG, and resuspended in phosphate buffered saline (PBS) to the original volume. Precipitates were used immediately or stored at $-20^{\circ} \mathrm{C}$.

MONOCLONAL ANTIHUMAN C 3 d

Monoclonal IgM antihuman C3d was prepared and its specificity tested at the South West Regional Blood Transfusion Centre as described elsewhere. ${ }^{11}$

ESTIMATION OF IMMUNOGLOBULIN BOUND B Y A N T - C 3 d

Monoclonal antihuman C3d $(10 \mu \mathrm{g} / \mathrm{ml})$ was incubated in the wells of polyvinyl plates (Linbro) for one hour at $37^{\circ} \mathrm{C}$ and one hour at $4^{\circ} \mathrm{C}$. Unbound antibody was removed and any free reactive sites blocked by incubation with $1 \%$ bovine serum albumin (BSA). Duplicate 1:10 dilutions of PEG precipitates were made in the wells and the plates incubated at $37^{\circ} \mathrm{C}$ for two hours. The plates were washed with $0.05 \%$ Tween 20 in phosphate buffered saline pH 7.2 (PBS-Tween). The amount of IgG attached to the plate was estimated by measuring the uptake of ${ }^{125}$ I labelled monoclonal antihuman IgG. Antihuman IgG was added to each well of the plate, the plates were incubated overnight at $4^{\circ} \mathrm{C}$, and the bound radioactivity counted. Counts obtained from control wells which had been incubated with BSA and antihuman IgG alone were subtracted from each sample count and the results expressed as a percentage of the total radioactivity added to each well.

The amounts of IgM and IgA bound by anti-C3d were estimated by measuring the uptake of monoclonal antihuman IgM and antihuman IgA.

Monoclonal anti-IgG and antihuman $\operatorname{IgA}$ were gifts from $\mathrm{Dr} J$ Lowe (Department of Immunology, Birmingham University). Antihuman IgM was obtained from Seward Immunostics (clone AF6). The specificities of these monoclonal antibodies were tested against purified myeloma proteins.

ESTIMATION OF RF BOUND BY ANTI-C3d

PEG precipitates were incubated on anti-C $3 \mathrm{~d}$ coated plates as described above, the plates were washed, and ${ }^{125}$ I labelled heat aggregated human IgG (Hagg) at a concentration of $1 \mu \mathrm{g} / \mathrm{ml}$ was added to each well of the plate. The plates were incubated overnight at $4^{\circ} \mathrm{C}$ and bound radioactivity counted. Counts obtained from control wells which had been incubated with BSA and Hagg alone were subtracted from each count and the results expressed as the percentage Hagg bound by each sample. 
SODIUM DODECYL SULPHATE-

POLYACRYLAMIDE GEL ELECTROPHORESIS

(S D S-PAGE)

This was carried out using the discontinuous buffer system. ${ }^{12}$ A $7.5 \%$ running gel and a $5 \%$ stacking gel were used.

\section{WESTERN BLOTTING}

Proteins separated by SDS-PAGE were transferred electrophoretically to nitrocellulose paper. ${ }^{13}$ Marker proteins were stained with $1 \%$ amido black and free reactive sites on the remainder of the paper blocked (1\% haemoglobin, $1 \%$ BSA). The position of proteins carrying C3d determinants was detected by overlaying the nitrocellulose paper with polyclonal anti-C3d. The paper was incubated in diluted antiserum for $30 \mathrm{~min}$ at room temperature, washed thoroughly in PBS-Tween, and blocked again with $0.5 \%$ BSA. Bound anti-C3d was detected with alkaline phosphatase labelled rabbit antihuman gamma chain (Sigma). Veronal buffer containing $0.5 \mathrm{mg} / \mathrm{ml}$ of naphthol AS:B1 phosphate (Sigma), $0.5 \mathrm{mg} / \mathrm{ml}$ of fast red dye, and $1 \mu \mathrm{l} / \mathrm{ml}$ of purpurin in dimethylformamide was used as the enzyme substrate. As the bands developed the reaction was stopped by rinsing the paper in water.

\section{ESTIMATION OF TOTAL C 3d}

C3d was measured by the double decker rocket immunoelectrophoresis method of Brandslund et $a l,{ }^{14}$ with some modifications. The samples were electrophoresed through two precipitating antibody gels: the first contained $40 \mu \mathrm{l} / \mathrm{ml}$ anti-C3c (Dakopatts, Copenhagen), thus precipitating C3 and C3c but allowing $\mathrm{C} 3 \mathrm{~d}$ to migrate into the second gel. This second gel contained anti-C $3 \mathrm{~d}(20 \mu \mathrm{l} / \mathrm{ml}$ of gel $)$, but PEG was not added. Polyclonal antihuman C3d was prepared at the South West Regional Blood Transfusion Centre. ${ }^{7}$ Volumes of synovial fluid ( $3 \mu \mathrm{l})$ and five dilutions of a standard serum (prepared from normal human serum incubated at room temperature for 10 days to allow the complete conversion of $\mathrm{C} 3$ to $\mathrm{C} 3 \mathrm{c}$ and $\mathrm{C} 3 \mathrm{~d}$ ) were applied to the gel. The results are expressed as a percentage of the amount of $\mathrm{C} 3 \mathrm{~d}$ in the standard serum.

COMPLEMENT CONSUMPTION ASSAY

The assay for complement consumption was performed as described previously. ${ }^{15} 16$ It involved the precipitation of complexes from sera with $2.5 \%$ PEG and an assay of the consumption of complement by the solubilised precipitate. The results were expressed as the highest serum dilution consuming $50 \%$ of the complement (fresh normal human serum) added.

C 1 q B IN DING AS SAY

This was performed as described elsewhere. ${ }^{17}$
RF A S A Y S

These radioimmunoassays were performed as detailed previously. ${ }^{18}$ Whole human IgG (for IgM RF assays or human IgG1 Fc for IgG RF assays) were used as antigen, and ${ }^{125} \mathrm{I}$ labelled monoclonal antiIgM and anti-IgG $\left(\mathrm{CH}_{1}\right)$ were the indicators for detecting the uptake of IgM and IgG respectively. The results were expressed as a percentage of the total labelled antibody bound by test samples.

\section{A F FINITY CHROMATOGRAPHY}

Cyanogen bromide activated Sepharose 2B-CL was washed in water and $0 \cdot 1 \mathrm{M}$ trisodium citrate $\mathrm{pH} 6.5$ before its incubation with either IgM anti-C3d or $\mathrm{F}(\mathrm{ab})_{2}$ fragments of anti-C3g (both at $5 \mathrm{mg} / \mathrm{ml}$ ) in citrate buffer overnight at $4^{\circ} \mathrm{C}$. After washing, residual active groups on the gel were blocked with $1 \mathrm{M}$ ethanolamine and the gel washed again.

Samples were incubated on Sepharose columns for $30 \mathrm{~min}$ at room temperature. Unbound material was eluted with phosphate buffered saline (PBS) and bound material with $0 \cdot 1 \mathrm{M}$ diethylamine $\mathrm{pH} 11$. The eluates were dialysed overnight against PBS, concentrated to the original volume of the sample, and their protein concentration estimated.

MONOCLONALANTI-C3g

The specificity of this IgG monoclonal antibody has been described. ${ }^{19}$ It was a gift from Professor P J Lachmann, Department of Pathology, University of Cambridge. The $\mathrm{F}(\mathrm{ab})_{2}$ fragment of this antibody was prepared by pepsin digestion and separation on ACA 34 before attaching it to Sepharose.

IM MUNOGLOBULIN LEVELS

The amounts of IgG in eluates from Sepharose antiC3d were measured by an inhibition assay. Plates were coated with purified IgG $(10 \mu \mathrm{g} / \mathrm{ml})$ and blocked with $1 \%$ BSA. A standard IgG solution $(100 \mu \mathrm{g} / \mathrm{ml})$ was diluted in some wells, and other samples were diluted to within the concentration range of the standard. ${ }^{125}$ I labelled anti-IgG was added to each well and the plate incubated for one hour at $37^{\circ} \mathrm{C}$ and one hour at $4^{\circ} \mathrm{C}$. After washing, the radioactivity bound to each well was counted. The radioactivity (uptake of anti- $\mathrm{Ig}$ ) is inversely proportional to the IgG concentration in the dilutions of the standard solution over a limited range. The concentration of the standard was plotted against the counts, and from this the concentration in the test samples was obtained.

\section{Results}

MEASUREMENT OF COMPLEMENT

ACTIVATING I g G

Not all immunoglobulins with bound complement 
components trigger the complement cascade. For example, 7S IgG bearing $\mathrm{C} 3$, which does not activate complement, ${ }^{20}$ can occur in RA sera. ${ }^{21}$ Consequently, immunoglobulin aggregates from the synovial fluid were freed from monomeric immunoglobulins (and from native C3) by $2.5 \%$ PEG precipitation before testing. Initial tests with PEG precipitates showed that much IgG was taken up by solid phase anti-C3d from RA synovial fluid (mean (SD) $7 \cdot 1(2 \cdot 0) \%$ anti-IgG bound, $n=12)$ but not from crystal arthropathy synovial fluid $(1 \cdot 6(2 \cdot 4) \%$, $\mathrm{n}=11$ ), where complement is activated but not by immunoglobulin aggregates, or from normal sera $(1.5(0.9) \%, n=20)$. IgG remaining in RA synovial fluid after PEG precipitation was not bound by solid phase anti-C3d.

It was important to test that the IgG attached to the solid phase was bound by anti-C3d antibodies. Accordingly, a comparison was made between the ability of IgM anti-C3d coated plates and plates coated with non-specific murine IgM to bind IgG from RA synovial fluid PEG precipitates. On average five times as much IgG was taken up on anti-C $3 \mathrm{~d}$ coated plates as on IgM coated plates. In another experiment solubilised PEG precipitates from RA synovial fluids were passed over anti-C3d

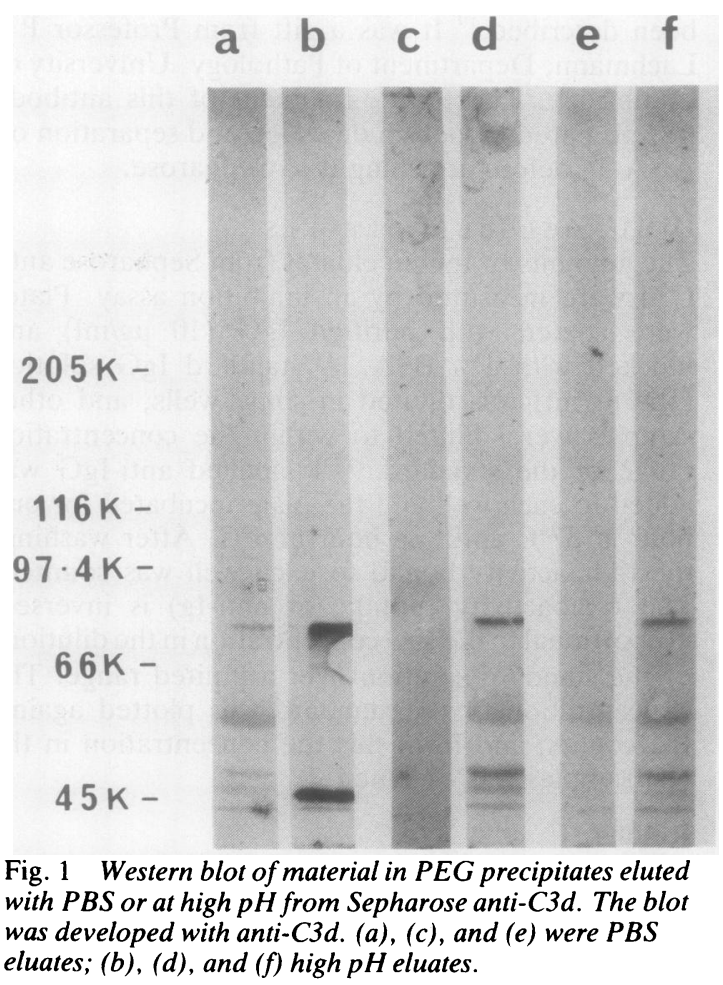

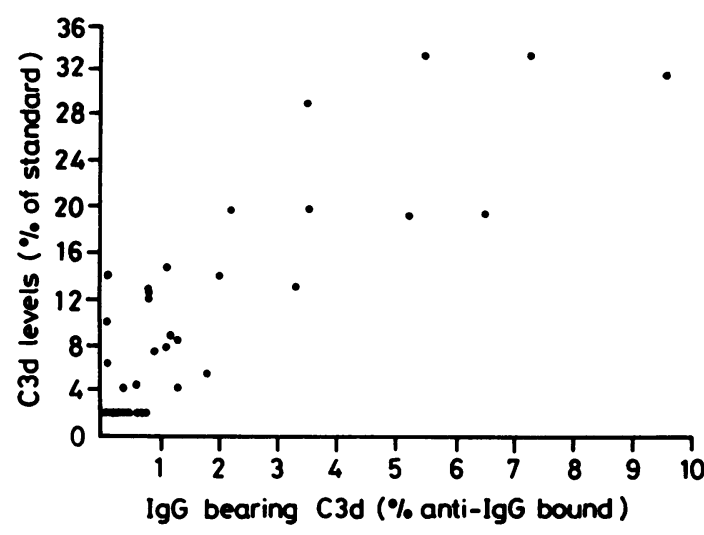

Fig. 2 Relation between the levels of C3d and aggregated IgG bearing C3d in RA synovial fluid.

Sepharose, the non-bound material collected, and the bound material eluted with $0 \cdot 1 \mathrm{M}$ diethylamine $\mathrm{pH}$ 11. The resultant fractions were separated by SDS-PAGE, transferred to nitrocellulose paper (Western blot), and the paper stained with alkaline phosphatase anti-C3d. Fig. 1 shows that the bound material (lanes b, d, and f) contained C3d, whereas the unbound material (lanes a, c, and e) contained either no C3d or less than the bound material. Presumably the band about $40 \mathrm{~K}$ is $\mathrm{C} 3 \mathrm{dg}$, and the higher molecular weight bands are either larger fragments of $\mathrm{C} 3$ or $\mathrm{C} 3 \mathrm{~d}$ attached to immunoglobulin fragments.

\section{CORRELATION BETWEEN AGGREGATED} IMMUNOGLOBULINS BEARING C 3 d AND COMPLEMENT ACTIVATION

If the IgG bound by solid phase anti-C3d were that responsible for complement activation in vivo then

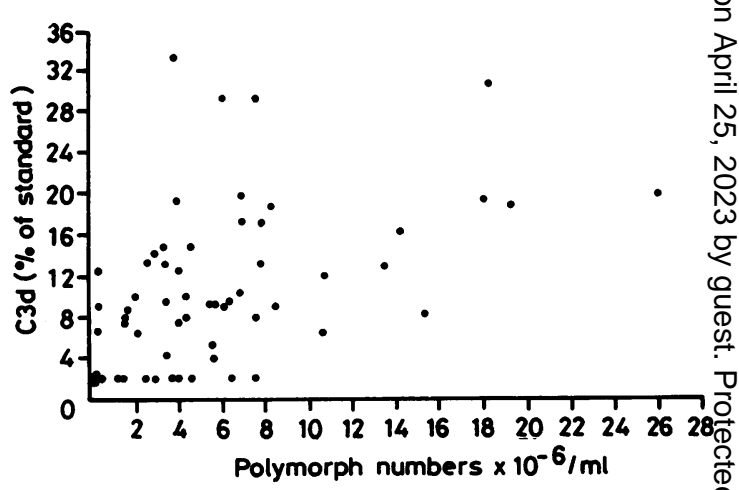

Fig. 3 Relation between polymorph numbers and C3d levels in RA synovial fluid. 
there should be a relation between the amount of IgG bound and the degree of complement breakdown in RA synovial fluid. Fig. 2 shows that a strong correlation $(n=38, r=0.89, p<0.0001)$ existed between IgG bearing C3d and C3d levels. It should be noted that the values for the amount of IgG bound by solid phase anti-C3d were obtained from one assay as some variation occurred between assays. The ability of anti-C3d to bind IgM and IgA from the PEG precipitates was also assayed. There were correlations between aggregated IgM bearing C $3 d$ and C3d levels $(r=0.55, p<0.01)$ and between aggregated IgA bearing $\mathrm{C} 3 \mathrm{~d}$ and $\mathrm{C} 3 \mathrm{~d}$ levels $(\mathrm{r}=0.61, \mathrm{p}<0.01)$.

Previous workers have investigated the correlation between C3d levels and immune complexes in RA synovial fluids but with conflicting results. For example, a strong correlation was reported between C3d levels and $\mathrm{C} 1 \mathrm{q}$ binding activity, ${ }^{22}$ but none between $\mathrm{C} 3 \mathrm{~d}$ levels and complement consuming activity. ${ }^{23} \mathrm{We}$, therefore, tested our RA synovial fluids for the levels of such complexes. Both complement consuming $(\mathrm{n}=31, \mathrm{r}=0.62, \mathrm{p}<0.001)$ and $\mathrm{C} 1 \mathrm{q}$ binding activity $(\mathrm{n}=35, \mathrm{r}=0.47, \mathrm{p}<0.01)$ correlated with C3d levels.

CORRELATION BETWEEN PMN NUMBERS AND COMPLEMENT ACTIVATION

High numbers of PMNs were found in most of the RA synovial fluids, and on average 62 (SD 23)\% (range $0-90 \%$ ) of the total white cells were PMNs. The possible influence of complement activation and of the complexes which triggered activation on the number of PMNs in synovial fluid was examined. As can be seen from Fig. 3 there was a correlation $(n=59, r=0 \cdot 50, p<0.001)$ between PMN numbers and C $3 \mathrm{~d}$ levels. A correlation was also

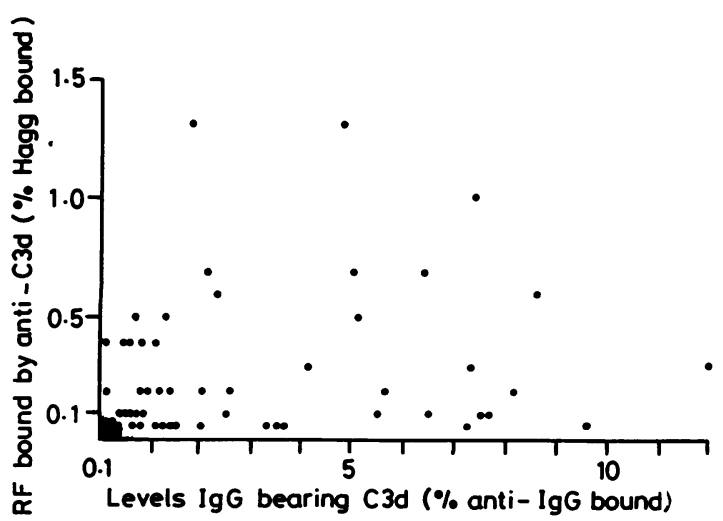

Fig. 4 Relation between levels of $R F$ bound by anti-C3d and levels of aggregated IgG bearing C3d.
Table 1 Relation between RF levels and C3d levels, PMN numbers, and assays of complement fixing complexes in $R A$ synovial fluids

\begin{tabular}{|c|c|c|c|c|c|c|}
\hline & \multicolumn{3}{|c|}{$I G M R F$} & \multicolumn{3}{|c|}{$\lg G R F$} \\
\hline & $n$ & $r$ & $p$ & $n$ & $r$ & $p$ \\
\hline C3d levels & 64 & 0.05 & NS & 62 & 0.02 & NS \\
\hline $\begin{array}{l}\text { PMN numbers } \\
\text { Aggregated IgG }\end{array}$ & 59 & 0.02 & NS & 62 & $0 \cdot 04$ & NS \\
\hline $\begin{array}{c}\text { bearing C3d } \\
\text { Aggregated IgM }\end{array}$ & 36 & 0.05 & NS & 36 & 0.01 & NS \\
\hline bearing $\mathrm{C} 3 \mathrm{~d}$ & 35 & 0.07 & NS & 36 & $0 \cdot 22$ & NS \\
\hline $\begin{array}{l}\text { Clq binding activity } \\
\text { Complement } \\
\text { consuming activity }\end{array}$ & 34 & 0.29 & NS & 28 & $0 \cdot 31$ & NS \\
\hline
\end{tabular}

found between PMN numbers and levels of aggregated IgG bearing C3d $(n=57, r=0 \cdot 50, p<0 \cdot 001)$.

DO IMMUNOGLOBULIN AGGREGATES BEARING C 3 d CONTAIN RF?

If the immunoglobulin aggregates which activated complement in RA synovial fluid contained RF then a relation might be expected between the levels of aggregated IgG bearing C3d and rheumatoid factor activity bound by anti-C3d in RA synovial fluid. Fig. 4 shows that no such correlation existed. Many of the synovial fluids with high levels of aggregated IgG bearing C3d (the range for normal sera in these experiments was $0 \cdot 2-0 \cdot 3 \%$ ) had low levels of rheumatoid factor activity bound by anti-C3d (range for normal sera $0 \cdot 08-0 \cdot 16 \%$ ). Similarly, there was no correlation between levels of aggregated IgM bearing C3d and rheumatoid factor bound by antiC3d $(r=0 \cdot 1, N S)$. In contrast, tests on 27 RA sera, selected because they contained detectable levels of aggregated $\mathrm{IgG}$ bearing $\mathrm{C} 3 \mathrm{~d}$, did show correlation $(r=0.47, p<0.02)$ between levels of aggregated IgG bearing $\mathrm{C} 3 \mathrm{~d}$ and rheumatoid factor activity bound by anti-C3d and also between levels of aggregated IgM bearing $\mathrm{C} 3 \mathrm{~d}$ and rheumatoid factor bound by anti-C3d $(r=0.58, p<0 \cdot 01)$.

If RFs are involved in complement activation (and PMN attraction) in RA synovial fluids then their levels should correlate with the degree of complement activation (and PMN numbers). Table 1 shows that neither IgM RF levels nor IgG RF levels correlated with C3d levels, PMN numbers, levels of aggregated immunogloblulin bearing $\mathrm{C} 3 \mathrm{~d}$, complement consuming activity, or $\mathrm{C} 1 \mathrm{q}$ binding activity.

SEPHAROSE ANTI-C 3 d

Rheumatoid factors from RA synovial fluids should be bound by Sepharose anti-C3d if complexes 
containing RF have activated complement. Accordingly, 20 synovial fluid PEG preciptates were incubated on Sepharose anti-C3d and the bound (diethylamine eluted) and unbound (PBS eluted) material tested for IgM RF and IgG RF activity. The results are shown in Figs 5 and 6. In 8/20 samples IgM RF was found in neither the PBS nor diethylamine eluates (group I), in five samples it was present only in the PBS eluates (group II), in one sample it occurred in only the diethylamine eluate (group III), and in six it occurred in both eluates (group IV) (Fig. 5). IgG RF was not detected in either eluate from 10/20 samples (group I), in six samples it was found in the PBS eluates alone (group II), and in four in both eluates (group IV). In all, 12/20 samples had neither IgG RF nor IgM RF in the bound eluate.

It could be argued that RF levels and immunoglobulin levels in the eluates are related and the absence of detectable RF in some eluates is due to their low content of immunoglobulin. To test this and determine directly which was the major immunoglobulin bound by Sepharose anti-C3d an estimate was made of the amount of $\operatorname{IgG}, \mathrm{JgM}$, and $\Rightarrow$. IgA in the eluates. The results for eight sampless (insufficient eluate was available from the othero samples to estimate all their immunoglobulin levels) $\underline{\underline{\underline{0}}}$ are given in Table 2. It is evident that IgG was the $\frac{\text { s. }}{9}$ major immunoglobulin bound by Sepharose anti- $-\widehat{D}$ C3d and that most of the bound fractions had lowere levels of immunoglobulin than their corresponding unbound fractions. No relation existed between? levels of IgM RF and IgM in the bound fraction $\vec{\omega}$ $(\mathrm{r}=0.52, \mathrm{NS})$ or between IgG RF activity and IgG in the bound fractions $(r=0 \cdot 29$, NS $)$.

In another experiment 12 synovial fluids were passed down Sepharose $\mathrm{F}(\mathrm{ab})_{2}$ anti-C $3 \mathrm{~g}$ and the. unbound material tested for IgM RF and IgG RF. $\overrightarrow{\mathrm{c}}$ The results were similar to those obtained with Sepharose anti-C3d except that higher levels of RF음 (IgM and IgG) were found in the unbound eluatesand only one unbound eluate contained no RF. ָू (This is because the synovial fluids contain uncomplexed RF, whereas their PEG precipitates do not.) In all, 4/12 bound eluates had detectable RF (four IgM RF and three IgG RF).
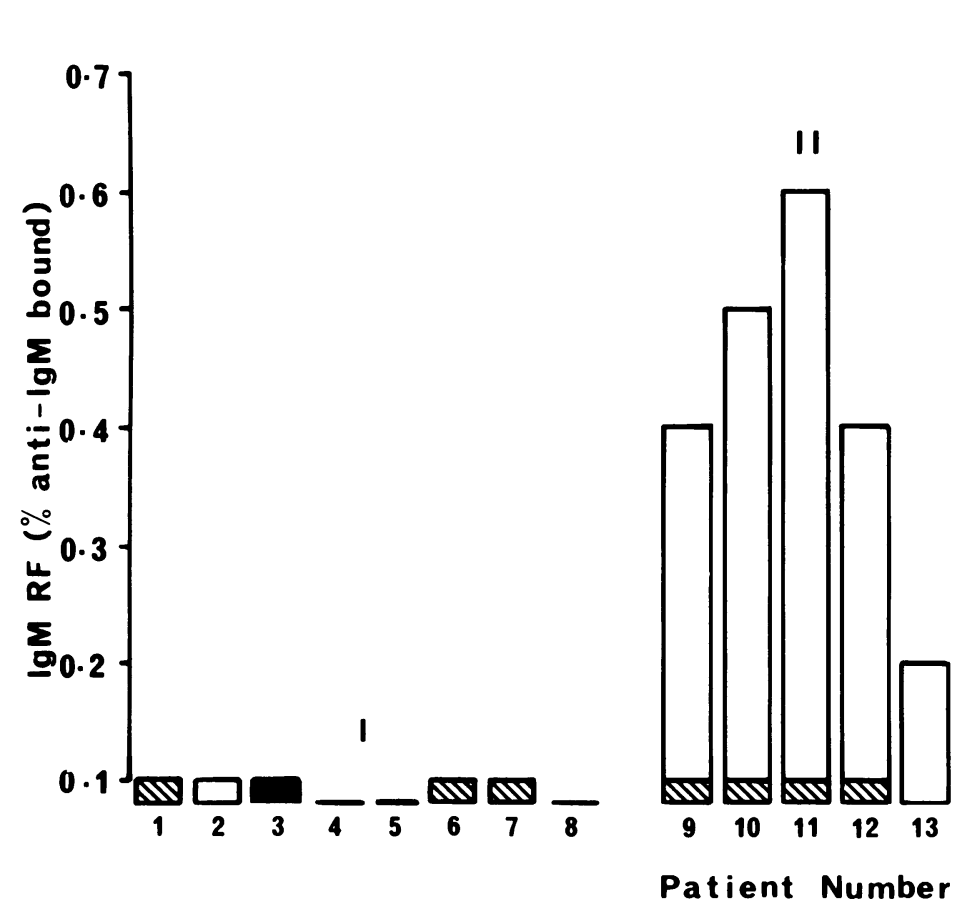

Fig. 5 Levels of IgM RF in fractions bound and unbound by Sepharose anti-C3d. The bars representing RF levels in both fractions are superimposed. $\mathbf{\square}=R F$ in bound fraction; $\square=R F$ in unbound fraction; $\mathbb{N}=R F$ in both fractions. The patients synovial fluids are divided into groups depending on whether $R F$ is absent from both fractions (I), present only in the unbound eluate (II), present only in the bound eluate (III), or found in both eluates (IV). 

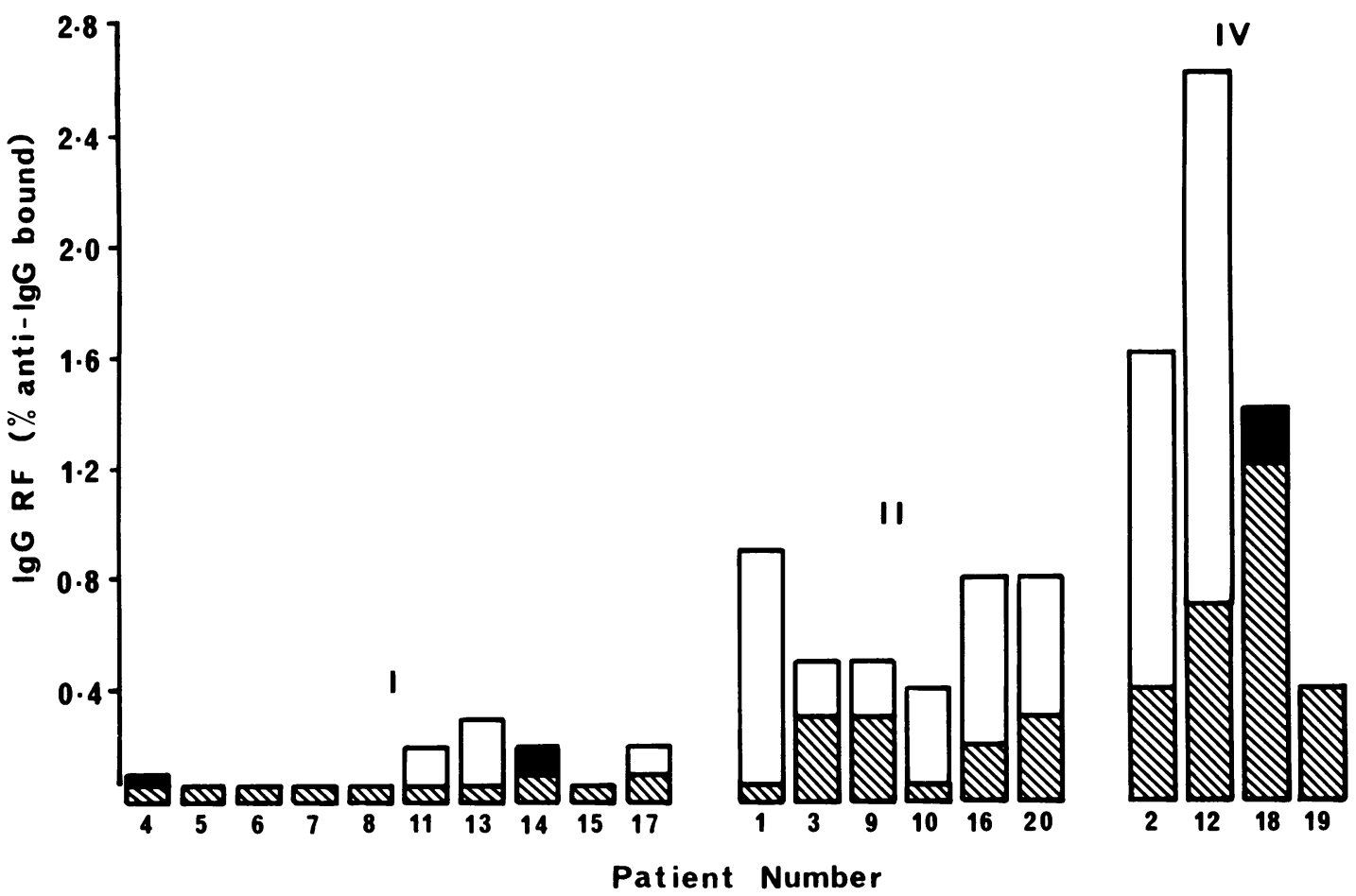

Fig. 6 Levels of IgG RF in fractions bound and unbound by Sepharose anti-C3d. The bars representing RF levels in both fractions are superimposed. $\square=R F$ in bound fraction; $\square=R F$ in unbound fraction; $\mathbb{Q}=R F$ in both fractions. The synovial fluids are divided into groups as in Fig. 5.

Table 2 Immunoglobulin levels in unbound $(U)$ and bound (B) material from Sepharose anti-C3d

\begin{tabular}{|c|c|c|c|c|c|c|}
\hline \multirow{3}{*}{$\begin{array}{l}\text { Patient } \\
\text { No }\end{array}$} & \multicolumn{6}{|c|}{ Immunoglobulin levels $(\mu \mathrm{g} / \mathrm{ml})$} \\
\hline & \multicolumn{2}{|l|}{$\lg G$} & \multicolumn{2}{|l|}{$\lg M$} & \multicolumn{2}{|l|}{$\operatorname{Ig} A$} \\
\hline & $U$ & $B$ & $U$ & $B$ & $U$ & $B$ \\
\hline 1 & $<4$ & 9 & $0 \cdot 8$ & 1 & 6 & 4 \\
\hline 3 & 43 & 6 & 3 & 0.5 & $<3$ & $<3$ \\
\hline 9 & 32 & 22 & 2 & 0.6 & 4 & $<3$ \\
\hline 10 & 36 & 23 & 7 & 4 & 4 & 4 \\
\hline 12 & 72 & 131 & 7 & 18 & 4 & 11 \\
\hline 15 & 39 & 3 & 13 & $<0.4$ & 4 & $<3$ \\
\hline 17 & 109 & 10 & 9 & 0.9 & 11 & $<3$ \\
\hline 18 & 91 & 82 & 12 & 3 & 7 & 13 \\
\hline
\end{tabular}

\section{Discussion}

The first question asked in this paper is whether the immunoglobulin aggregates bound by solid phase anti-C3d from RA synovial fluid are responsible for complement activation in the rheumatoid joint. C3 is the central component of the complement pathway and measurement of its breakdown products reflects activation by initiators of both the classical and alternate pathways. The cleavage of $\mathrm{C} 3$ by its convertases exposes the metastable binding site of $\mathrm{C} 3$, and such $\mathrm{C} 3$ rapidly (the binding site has a half life of about $60 \mu \mathrm{s}^{24}$ ) becomes covalently linked to any acceptor molecules in the immediate microenvironment. Most activated $\mathrm{C} 3$ reacts with water and quickly breaks down to free $\mathrm{C} 3 \mathrm{~d},{ }^{25}$ while the remainder reacts with, and is retained on, the material which activated the earlier components. ${ }^{2627} \mathrm{C} 3 \mathrm{~d}$ levels are thought to reflect the degree of complement activation in vivo ${ }^{28}$ and in vitro $^{29}$ because $\mathrm{C} 3 \mathrm{~d}$ has the longest half life (50 hours) of the $\mathrm{C} 3$ breakdown products. ${ }^{28} \mathrm{We}$, therefore, investigated the correlation between C3d levels and immunoglobulin aggregates in RA synovial fluids. Correlations were obtained between $\mathrm{C} 3 \mathrm{~d}$ levels and both $\mathrm{C} 1 \mathrm{q}$ binding and complement consuming (anticomplementary) activity. The strongest correlation observed, however, was between C3d levels and levels of aggregated IgG 
bearing $\mathrm{C} 3 \mathrm{~d}$, implying that this $\mathrm{C} 3 \mathrm{~d}$ binding assay gives a more accurate measurement of those complexes which activate complement than do other assays. The strong correlation shown also provides further support for the hypothesis that immune complexes, particularly those containing IgG, are the major cause of complement activation in RA synovial fluid and agrees with the quantitative results which showed that $\operatorname{IgG}$, rather than IgM or $\operatorname{IgA}$, was the major immunoglobulin bound by antiC3d.

If the principal PMN attractants in the joint space are complement breakdown products then there should be a relation between PMN numbers and both the levels of complement activation and the levels of complexes which activated complement. This expectation was, at least in part, borne out by the results. Previously, a relation between C3d levels and synovial fluid PMN numbers was observed in a group consisting of equal numbers of patients with seropositive and seronegative RA. ${ }^{30}$ As both PMN numbers and C3d levels were lower in seronegative than in seropositive synovial fluids then amalgamating the two subgroups might have influenced the correlation. Using a larger group of synovial fluids mainly from seropositive patients, we found a similar correlation. There are a number of reasons why the correlation between PMN numbers and C3d levels is not higher. For example, other PMN attractants, such as leucotriene $\mathrm{B} 4^{31}$ and interleukin $1,{ }^{32}$ occur in RA synovial fluid,,$^{31}$ and these too may play a part in attracting PMN. Another possibility is that some lymphokines which decrease PMN motility ${ }^{34}$ may be present in synovial fluid if a $\mathrm{T}$ cell mediated immune reaction occurs in the joint. However it may be, the correlations demonstrated firmly implicate complexed immunoglobulins bearing $\mathrm{C} 3 \mathrm{~d}$ as being those intimately involved in complement activation and PMN attraction in RA synovial fluid.

The main conclusion drawn from this study must be that synovial fluid complexes containing RF are not those primarily responsible for activating complement or attracting PMN into the joint cavity of most patients with RA. Firstly, no correlation was found between the levels of aggregated immunogloblins which activate complement in RA synovial fluid (aggregated IgG bearing C3d and IgM bearing C3d) and complement fixing complexes which contain RF (RF activity bound by anti-C3d). Secondly, analysis of the immunoglobulins bound from most RA synovial fluid by Sepharose anti-C3d (and Sepharose anti-C3g) showed no RF activity. This activity was not related to the overall levels of IgG (or IgM) bound by Sepharose anti-C3d as some eluates with high IgG or IgM levels contained no RF activity, and conversely, some eluates with low $\operatorname{IgG}$ (or IgM) levels had appreciable RF activity.

Although RF levels have been shown to correlate with complement activation in the sera of patiente with RA, ${ }^{35-37}$ similar studies with synovial fluid, i agreement with the results presented here, hav failed to find a relationship. ${ }^{38-40}$ One study claimed to show that RF in synovial fluid was related to. complement activation. ${ }^{10}$ The sample of 32 fluids? however, included that from nine patients with non-rheumatoid arthritis and all had low complew ment conversion and no rheumatoid factor. Thu the conclusion that complement and RF werg related is invalid.

It could be argued that RF, particularly synoviat fluid RF, is unable to activate complement. IgM RG isolated from sera, however, has been clearly show $\underline{B}$ to activate complement in a solid phase assay with reduced and alkylated IgG as antigen. ${ }^{41}{ }^{42}$ Similarlye complement activation by IgG RF from serum ha? also been demonstrated in both solid and fluid phase complexes, ${ }^{43}$ though it is far less efficient than an. equivalent amount of IgM RF. Thus there is n\& doubt that under the correct conditions RF can activate complement. Furthermore, IgM RF iso lated from two RA synovial fluids activated comples ment in the solid phase assay, ${ }^{44}$ suggesting that ther are no differences between sera and synovial fluieg RF in their ability to activate complement. appears, however, that IgM RF can have an inhibitory effect on complement activation by im mune complexes, and this effect varies with the original size of the complex; the complement fixing activity of larger aggregates is reduced more drama. tically than that of smaller complexes. ${ }^{45}$ The facto that complexes other than those containing RF are responsible for activating complement in man synovial fluids might be explained by the locad conditions in the joint cavity. For example, local production of RF may affect the size and interas tions of immune complexes. Thus the effect of interaction of immune complexes with RF may be ti․ increase complement activation in the circulation but to inhibit it in synovial fluid.

In agreement with other workers ${ }^{6}$ we have beef unable to detect anything other than immunoglobu诃 lins and complement components in the comple ment activating aggregates isolated from RA syb ovial fluid, ${ }^{46}$ but neither was RF found in many of the aggregates. Therefore the question arises of how the complement activating aggregates are formedo Recent work has suggested a mechanism for the aggregation of IgG in rheumatoid synovial fluic Immunoglobulins isolated from the sera of patien $\overrightarrow{8}$ with RA show an increased percentage of proteins carrying a particular oligosaccharide as compared 
with normal individuals. ${ }^{47}$ This oligosaccharide leaves sites of intramolecular protein/sugar interaction vacant, possibly creating a lectin-like activity and resulting in IgG from patients with RA being especially prone to form aggregates. It may be that this property of RA IgG allows it to self aggregate in the absence of antigen, or allows complexes to form at a very low antigen concentration. In the same way complexes may remain aggregated after antigen or antibody (RF) has dissociated. Thus complement fixing complexes would be detected by immune complex assays, but neither antigen nor RF would necessarily be present.

This work was supported by grants from the Arthritis and Rheumatism Council and Nuffield Foundation.

\section{References}

1 Zvaifler $\mathrm{N} \mathrm{J}$. The immunopathology of joint inflammation in rheumatoid arthritis. Adv Immunol 1973; 16: 265-336.

2 Winchester R J. Agnello V. Kunkel H G. Gamma globulin complexes in synovial fluid of patients with rheumatoid arthritis. Partial characterisation and relationship to lowered complement levels. Clin Exp Immunol 1970; 6: 689-706.

3 Zvaifler N J. Breakdown products of $\mathrm{C} 3$ in human synovial fluids. J Clin Invest 1969; 48: 1532-42.

4 Perrin L H, Nydegger V E, Zubler R H, Lambert $P$ H, Miescher P A. Correlation between levels of breakdown products of $\mathrm{C} 3, \mathrm{C} 4$ and properdin factor $\mathrm{B}$ in synovial fluids from patients with rheumatoid arthritis. Arthritis Rheum 1977; 20: $647-52$.

5 Ruddy S, Austen K F. The complement system in rheumatoid synovitis $\mathrm{I}$. An analysis of complement component activities in rheumatoid synovial fluids. Arthritis Rheum 1970; 13: 713-23.

6 Male D K. Roitt I M. Molecular analysis of complement fixing rheumatoid synovial fluid immune complexes. Clin Exp Immunol 1981; 46: 521-9.

7 Elson C J. Scott D G I, Blake D, Bacon P A. Hoult P G I. Complement activating rheumatoid factor containing complexes in patients with rheumatoid vasculitis. Ann Rheum Dis 1983; 42: $147-50$.

8 Elson C J, Carter S D. Cottrell B J. Scott D G I, Bacon P A. Wallington $\mathrm{T}$. Complement activating properties of complexes containing rheumatoid factor in synovial fluids and sera from patients with rheumatoid arthritis. Clin Exp Immunol 1985; 59: 285-92.

9 Male D K, Roitt I M. Hay F C. Analysis of immune complexes in synovial effusions of patients with rheumatoid arthritis. Clin Exp Immunol 1980; 39: 297-306.

10 Hedberg H. Lundh B. Laurell A B. Studies of the third component of complement in synovial fluid from arthritic patients. Clin Exp Immunol 1970; 6: 707-12.

11 Holt P J D. Donaldson C. Judson P A. Johnston P. Parsons S F, Anstee D J. NBTS/BRIC8: a monoclonal anti-C3d antibody. Transfusion 1985: 25: 267-79.

12 Laemelli U K. Cleavage of structural proteins during the assembly of the head of bacteriophage T4. Nature 1970; 227: 680-5.

13 Towbin H. Stachelin T, Gordon J. Electrophoretic transfer of proteins from polyacrylamide gels to nitrocellulose sheets. Proc Natl Acad Sci USA 1979; 76: 4350-4.

14 Brandslund I, Siersted H C, Svehag S E, Teisner B. Double decker rocket immunoelectrophoresis for direct quantitation of complement $\mathrm{C} 3$ split products with $\mathrm{C} 3 \mathrm{~d}$ specificities in plasma. J Immunol Methods 1981; 44: 63-71.
15 Harkiss G D, Brown D L. Detection of immune complexes by a new assay, the polyethylene glycol precipitation complement consumption test. Clin Exp Immunol 1979; 36: 117-29.

16 Grace S A, Elson C J. Continuous production of anti-host IgG antibodies contained in circulating IgG-anti-IgG complexes. Immunology 1982; 47: 289-96.

17 Verrier-Jones J, Cummings R H. Tests for circulating immune complexes. In: Thompson $\mathrm{R}$ A, ed. Techniques in clinical immunology. Oxford: Blackwell, 1977: 136-57.

18 Elson C J, Carter S D. Scott D G I, Bacon P A, Lowe J. A new assay for IgG rheumatoid factor activity and its use to analyse rheumatoid factor reactivity with human IgG isotypes. Rheumatol Int 1985; 5: 175-9.

19 Lachmann P J, Oldroyd R, Milstein C, Wright B W. Three rat monoclonal antibodies to human C3. Immunology 1980; 41: 503-15.

20 Jacobs R J, Reichlin M. Generation of low molecular weight, C3 bearing immunoglobulin in human serum. J Immunol 1983; 130: $277-8$.

21 Pereira A B. Theofilopoulos A N. Dixon F J. Detection and partial characterisation of circulating immune complexes with solid phase anti-C3. J Immunol 1980; 125: 763-70.

22 Nydegger V E, Zubler R H. Gabay R, et al. Circulating complement breakdown products in patients with rheumatoid arthritis. J Clin Invest 1977; 59: 862-8.

23 Berkowicz A, Kappelgaard E, Petersen J, et al. Complement $\mathrm{C} 3 \mathrm{c}$ and $\mathrm{C} 3 \mathrm{~d}$ in plasma and synovial fluid in rheumatoid arthritis. Acta Pathol Microbiol Immunol Scand [C] 1983; 91: 397-402.

24 Sim R B. Twose D S. Sim E. The covalent binding reaction of complement component C3. Biochem J 1981; 193: 115-27.

25 Ross G D, Medof M E. Membrane complement receptors specific for bound fragments of C3. Adv Immunol 1985; 37: 217-67.

26 Law S K. Fearon D T. Levine R P. Action of the C3binactivator on cell-bound C3b. J Immunol 1979; 122: 759-65.

27 Gadd K J, Reed K B M. The binding of complement component $\mathrm{C} 3$ to antibody antigen aggregates after activation of the alternative pathways in human serum. Biochem J 1981; 195: 471-80.

28 Charlesworth J A. Williams D G. Naish P, Lachmann P J, Peters D K. Metabolism of radio-labelled C3-effects of in vivo activation in rabbits. Clin Exp Immunol 1974; 16: 445-52.

29 Perrin L H. Lambert P H. Miescher P A. Complement breakdown in plasma from patients with systemic lupus erythematosus and patients with membranoproliferative or other glomerulonephritis. J Clin Invest 1975; 56: 165-76.

30 Hunder G G. McDuffie F C. Muller B J. Activation of components $\mathrm{C} 3$ and factor B in synovial fluids. $\mathrm{J} \mathrm{Lab} \mathrm{Clin} \mathrm{Med}$ 1977; 89: 160-71.

31 Klickstein L B, Shapleigh C. Goetzl E J. Lipoxygenation of arachidonic acid as a source of polymorphonuclear leukocyte chemotactic factors in synovial fluid and tissue in rheumatoid arthritis and spondyloarthritis. $J$ Clin Invest 1980; 66: 1166-70.

32 Saunder D N. Mounessa N L. Katz S I. Dinarello C A, Gallin J I. Chemotactic cytokines: the role of leukocyte pyrogen and epidermal cell thymocyte-activating factor in neutrophil chemotaxis. J Immunol 1984; 132: 828-32.

33 Wood D D, Ihrie E J, Dinarello C A. Gallin J I. Isolation of an interleukin-1 like factor from human joint effusions. Arthritis Rheum 1983; 26: 975-83.

34 Weisbart R H, Golde D W, Clark S C. Wong G G. Gasson J C. Human granulocyte-macrophage colony stimulating factor is a neutrophil activator. Nature 1983; 314: 361-3.

35 Zvaifler $\mathbf{N}$ J. Breakdown products of $\mathrm{C}^{\prime} 3$ in human synovial fluids. J Clin Invest 1969; 48: 1532-42.

36 Kaplan R A. Curd J G, Deheer D H, et al. Metabolism of C4 and factor $\mathrm{B}$ in rheumatoid arthritis. Relation to rheumatoid factor. Arthritis Rheum 1980; 23: 911-20. 


\section{Bedwell, Elson, Carter, Dieppe, Hutton, Czudek}

37 Reyes P A, Gobaira Maluf J, Curd J G, Vaughan J H. Association of rheumatoid factor with complement activation in rheumatoid arthritis and other diseases. Clin Exp Immunol 1983; 53: 391-6.

38 Pekin $\mathrm{T} \mathbf{J}$, Zvaifler $\mathrm{N} \mathbf{J}$. Haemolytic complement in synovial fluid. J Clin Invest 1964; 43: 1372-82.

39 Townes A S, Marcu R L. Complement activating activity of rheumatoid synovial fluid. Ann Rheum Dis 1972; 31: 393-401.

40 Inman $\mathrm{R}$ D, Harpel P C. C1 inactivator-C1s complexes in inflammatory joint disease. Clin Exp Immunol 1983; 53: 521-8.

41 Tanimoto K. Cooper N S, Johnson J S, Vaughan J H. Complement fixation by rheumatoid factor. J Clin Invest 1975; 55: $437-45$.

42 Sabharwal U K, Vaughan J H. Fong S, Bennett P H, Carson D A, Curd J G. Activation of the classical pathway of complement by rheumatoid factors. Arthritis Rheum 1982; 25: 161-7.
43 Brown P B, Nardella F A, Mannick M. Human complemen? activation by self-associated rheumatoid factors. Arthriti Rheum 1982; 25: 1101-7.

44 Taylor-Upsahl M M, Johnson P M, Mellbye O J. A study of complement activation by rheumatoid factor using a haemolytif assay system. Clin Exp Immunol 1977; 28: 204-11.

45 Doekes G. Schouten J, Cats A. Daha M R. Reduction of the complement activation capacity of soluble IgG aggregates an immune complexes by IgM rheumatoid factor. Immunolog 1985; 55: 555-64.

46 Bedwell A E. Immunological abnormalities of rheumatoig arthritis. Bristol University, 1986. (PhD thesis.)

47 Parekh R B, Dwek R A, Sutton B J, et al. Association of rheumatoid arthritis and primary osteoarthritis with changes im the glycosylation pattern of total serum IgG. Nature $1985 ; 316 \mathrm{NO}$ $452-7$. 